\title{
Produtividade do feijão-caupi cultivado após plantas de cobertura com e sem aplicação de herbicidas em pós-emergência
}

Gustavo Dorneles de Sousa', Leandro Spíndola Pereira ${ }^{3}$, Gustavo Silva de Oliveira', Estevam Matheus Costa ${ }^{2}$, Jeovane Nascimento Silva', Higor Ferreira da Silva', Adriano Jakelaitis ${ }^{1}$

${ }^{1}$ Instituto Federal Goiano - IF Goiano, GO. ${ }^{2}$ Instituto Goiano de Agricultura - IGA, GO. ${ }^{3}$ Instituto Goiano de Agricultura - IGA, GO. E-mail: leandrop629@gmail.com.

\begin{abstract}
Resumo
Objetivou-se avaliar o rendimento e as características produtivas da cultura do feijão-caupi, quando cultivada sobre palhadas de plantas de cobertura, manejadas ou não com herbicidas aplicados em pósemergência. $O$ experimento foi conduzido em campo, em delineamento de blocos completos ao acaso, com três repetições. Em esquema fatorial $5 \times 2$, foram testados cinco tipos de palhadas: sorgo, capim-ruziziensis, capim-tanzânia, capim-marandu e plantas daninhas (primeiro fator), combinados com a ausência e a aplicação da mistura pronta de bentazona + imazamoxi na dose $600+28 \mathrm{~g} \mathrm{ha}^{-1}$ aos 13 dias após a emergência (DAE) e do herbicida haloxifope-p-metílico na dose de $62,35 \mathrm{~g} \mathrm{ha}^{-1}$ aos 18 DAE (segundo fator). Foram avaliadas a densidade e a massa seca de plantas daninhas aos 20 e 85 DAE da cultura, a altura de plantas, o diâmetro da haste, o teor de clorofila e a massa da parte aérea no florescimento da cultura (46 $\mathrm{DAE})$. Na colheita, avaliaram-se o número de grãos por vagens, o número de grãos por planta, o peso de mil grãos, a população de plantas de feijão-caupi e o rendimento de grãos. As palhadas de capim-ruziziensis, capim-tanzânia e capim-marandu sobre a superfície do solo reduzem a massa seca de plantas daninhas, constituindo manejo necessário onde o controle químico não foi realizado. Independente do uso de palhada, a aplicação de herbicidas é essencial para garantir a produtividade da cultura. 0 cultivo de feijãocaupi sobre as palhadas de sorgo, capim-ruziziensis, capim-tanzânia e capim-marandu resultam em maior rendimento de grãos.
\end{abstract}

Palavras-chave: palhada; comunidade infestante; Vigna unguiculata.

\section{Effects of straw and herbicide application in the cowpea culture}

\begin{abstract}
The objective of this research was to evaluate the yield of the cowpea crop, when grown on cover crops straws, managed or not with herbicides applied in post-emergence. The experiment was conducted in the field, in a complete randomized block design with three replications. In a $5 \times 2$ factorial scheme, the first factor were featured by five types of straw were tested: sorghum, congo grass, Tanzania grass, palisadegrass and weeds. The second factor was characterized by the absence and application of the ready mix of bentazone + imazamox at the dose $600+28 \mathrm{~g} \mathrm{ha}^{-1}$ at 13 days after emergence (DAE) and the herbicide haloxifop-p-methyl at the dose of $62.35 \mathrm{~g} \mathrm{ha}^{-1}$ to 18 DAE. Weed density and dry matter were evaluated at 20 and 85 DAE of the crop, plant height, stem diameter, chlorophyll content, dry matter aerial part and in the flowering of the crop (46 DAE). At harvest, the number of grains per pod, the number of grains per plant, the weight one hundred grains, the population of cowpea plants and grain yield were evaluated. The straws of congo grass, Tanzania grass and palisadegrasson the soil surface reduce the dry mass of weeds, constituting necessary management where chemical control has not been carried out. Regardless of the use of straw, the application of the herbicide is essential to guarantee the productivity of the crop. The cultivation of cowpea on sorghum straw, congo grass, Tanzania grass and palisadegrass results in higher grain yield.
\end{abstract}

Keywords: straws; weed community; Vigna unguiculata. 


\section{Introdução}

O feijão-caupi (Vigna unguiculata), conhecido popularmente por feijão-de-corda, é uma cultura de grande importância socioeconômica regional, sendo cultivado em regiões de menor poder aquisitivo, como o Norte e Nordeste brasileiro (BRASIL, 2018). Destaca-se pela elevada qualidade nutricional de seus grãos, sendo amplamente cultivada por pequenos produtores, principalmente em solos de baixa fertilidade, e em regiões de baixo índice pluviométrico (RIBEIRO et al., 2002).

Nos últimos anos, a cultura vem ganhando destaque na região Centro-Oeste, devido à rentabilidade econômica e ao desenvolvimento de cultivares eretas e semieretas, que favorecem a colheita mecanizada. Segundo dados de Freire Filho et al. (2011) em 2006, o Centro-Oeste cultivava feijão-caupi em uma área de 3.464 hectares e em 2017 a área plantada cresceu de forma expressiva, atingindo 248.100 hectares. Contudo, ainda é uma cultura que necessita de desenvolvimento de pesquisa e de tecnologia, para aumentar a produtividade e evitar perdas (PEREIRA et al., 2020).

A interferência de plantas daninhas é um dos elementos responsáveis por diminuir a produção do feijão-caupi, visto que quando o controle não é o suficiente, ocorre redução do estande final de plantas, do número de vagens e grãos por planta, e, consequentemente, do rendimento de grãos do feijão-caupi, gerando até $90 \%$ de perdas (MATOS et al., 1991). Segundo Freitas et al. (2009), essas altas perdas estão relacionadas com fato das plantas daninhas competirem diretamente com a planta cultivada por luz, nutrientes e água, além de indiretamente, onerarem custos no processo de colheita, secagem e beneficiamento dos grãos.

Para o feijão-caupi cv BRS Guariba o período crítico de prevenção à interferência (PCPI) de plantas daninhas situa-se entre oitavo e quinquagésimo terceiro dias após a emergência, ou seja, esse é o intervalo em que as plantas daninhas devem ser controladas na cultura, para não haver perda significativa na produtividade (CORRÊA et al., 2016). Portanto, dentre as técnicas utilizadas a fim de manejar as plantas daninhas, destaca-se a utilização de herbicidas, associada a outras técnicas, como semeadura sob palhada de plantas de cobertura (CORREIA et al., 2006).

A utilização de plantas de cobertura, visando a produção de palhada, pode ser utilizada no intuito de reduzir o efeito da interferência de plantas daninhas, reduzindo a utilização de herbicidas, além de promover uma série de benefícios ao solo, como: manutenção da umidade do solo, disponibilização de nutrientes e criação de ambiente favorável para a microbiota do solo (CORREIA et al., 2006.; NOCE et al., 2010).

Diante do exposto, objetivou-se avaliar a resposta de plantas de feijão-caupi, quando cultivadas sobre palhadas de plantas de cobertura e sobre pousio, manejadas ou não com herbicidas aplicados em pós-emergência.

\section{Material e Métodos}

O experimento foi conduzido no campo experimental do Instituto Federal Goiano Campus Rio Verde, no período de março a junho de 2018 , situado nas coordenadas geográficas $17^{\circ}$ $48^{\prime} 28.2^{\prime \prime} \mathrm{S}$ e $50^{\circ} 54^{\prime} 39^{\prime \prime} \mathrm{O}$ e altitude de 720 metros. A precipitação total durante a pesquisa foi de $270,1 \mathrm{~mm}$ e a temperatura média foi de 25,6C (INMET, 2018). O solo da região é classificado como Latossolo Vermelho distroférrico, e o clima é do tipo Aw mesotérmico, tropical de savana, segundo a classificação de Köppen.

A análise de solo apresentou na profundidade de 0 a $20 \mathrm{~cm}$, a seguinte composição físico-química: $\mathrm{pH}$ 6,2 (SMP), Ca de 4,64 $\mathrm{cmolc} \mathrm{dm}^{-3}, \mathrm{Mg}$ de 2,50 $\mathrm{cmolc} \mathrm{dm}^{-3}, \mathrm{Al} 3+\mathrm{de}$ $0,04 \mathrm{cmolc} \mathrm{dm}^{-3}, \mathrm{H}+\mathrm{Al}$ de $4,5 \mathrm{cmolc} \mathrm{dm}^{-3}$, CTC de

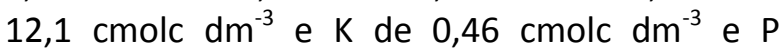
(Melich) de 13,1 $\mathrm{mg} \mathrm{dm}^{-3}$, matéria orgânica de $3,62 \mathrm{mg} \mathrm{dm}^{-3}$ e Zn 4,5 mg dm${ }^{-3}$, saturação por bases de $62,8 \%$, saturação por alumínio de $0,5 \%$, argila de $64,5 \%$, silte $10,0 \%$ e areia de $25,5 \%$. 0 preparo do solo foi realizado por meio de sistema convencional, com duas arações e gradagens, seguido da abertura de sulcos, com cultivador contendo hastes espaçadas a $0,5 \mathrm{~m}$. Não foi realizado correção do solo, e a adubação foi feita somente na semeadura do feijão-caupi.

Foram semeadas manualmente as espécies de cobertura: Sorghum bicolor, Urochloa ruziziensis, Urochloa brizantha cv. Marandu e Panicum maximum cv Tanzânia, e 90 dias após a semeadura, procedeu-se a dessecação química com glifosato na dose de 1.440 g e.a. ha ${ }^{-1}$. Visto que a ideia do trabalho era a formação de palhadas, as espécies forrageiras (S. bicolor, $U$. ruziziensis, $U$. brizantha e $P$. maximum) foram semeadas adotando a recomendação de 600 pontos de valor cultural (VC), e o S. bicolor semeado na população de 110.000 plantas por 
hectare.

Aos 15 dias após a dessecação, realizouse a semeadura direta do feijão-caupi cultivar BRS Guariba (porte semi-ereto e grãos brancos) sobre as diferentes palhadas formadas.

O delineamento experimental utilizado foi o de blocos completos ao acaso, com três repetições, sendo que cada parcela foi composta por 5 linhas de feijão-caupi, espaçadas a 0,45 m, com $5 \mathrm{~m}$ de comprimento totalizando $11,25 \mathrm{~m}^{2}$ $(2,25 \mathrm{~m} \times 5 \mathrm{~m})$. Adotou esquema fatorial $5 \times 2$, com a semeadura de feijão caupi sobre as palhadas das gramíneas: Sorghum bicolor, Urochloa ruziziensis, Urochloa brizantha cv. Marandu e Panicum maximum cv Tanzânia, mais a área de pousio, constituída por palhada dessecada de plantas daninhas (primeiro fator). 0 segundo fator foi constituído pela ausência e pela aplicação de herbicidas em pós-emergência.

As sementes do feijão-caupi foram inoculadas com Bradyrhizobium sp. e tratadas com Standak Top, seguindo a recomendação do fabricante. A semeadura foi mecanizada, sendo depositadas 12 sementes de feijão por metro, a três $0,03 \mathrm{~m}$ de profundidade, com espaçamento entre linhas de $0,45 \mathrm{~m}$. A adubação de semeadura foi de $300 \mathrm{~kg} \mathrm{ha}^{-1}$ da formulação 04-14-08.

Os herbicidas, foram aplicados aos 13 e 18 dias após a emergência (DAE) da cultura, com pulverizador pressurizado por $\mathrm{CO}_{2}$, equipado com barra de quatro pontas TT 11002 , espaçadas de $0,50 \mathrm{~m}$, posicionados a $0,5 \mathrm{~m}$ de altura em relação à superfície das plantas, com um volume de calda de $200 \mathrm{~L} \mathrm{ha}^{-1}$ e pressão de trabalho de 2,5 bar, no período matutino, entre 7:00h e 9:30h, com temperatura do ar entre 26,3 a 27,7 ${ }^{\circ} \mathrm{C}$; umidade relativa do ar entre 67,4 a $74,2 \%$, velocidade do vento inferior a $1,0 \mathrm{~m} \mathrm{~s}^{-1}$ e solo úmido à superfície.

Aos 13 DAE foi usado a mistura pronta de bentazona + imazamoxi (Amplo $\left.{ }^{\circ}\right)$, na dose de 600 $+28 \mathrm{~g}$ i.a ha ${ }^{-1}$ para o controle de plantas daninhas eudicotiledôneas. Aos 18 DAE foi aplicado o herbicida haloxifope-p-metílico (VerdictR ${ }^{\circ}$ ) na dose de 62,35 g i.a ha ${ }^{-1}$ para o controle de Poaceaes. As parcelas adjacentes às aplicadas foram protegidas no momento da aplicação com lona plástica para evitar à deriva. Durante a condução do experimento, realizou somente uma a aplicação de Deltametrina (Keshet $25 \mathrm{EC}$ ), na dose de 0,3 L por hectare visando o controle de insetos sugadore e mastigadoress, quando as plantas de feijão situavam estádio fenológico $R_{1}$. Não foram realizados tratamentos fitossanitários para doenças do feijoeiro, devido à baixa incidência.

Aos 20 DAE e no ponto da colheita ( 85 DAE), realizou-se o levantamento de plantas daninhas, através do lançamento ao acaso de dois quadrados vazados com dimensões de 50×50 $\mathrm{cm}$. As plantas daninhas, situadas no interior dos quadrados, foram identificadas, coletadas, separadas, e acondicionadas em sacos de papel e conduzidas à estufa de renovação e circulação forçada de ar a 65 ㅇ $\mathrm{C}$ por 72 horas, até atingir massa constante, sendo posteriormente, pesadas.

No florescimento da cultura (46 DAE), foram colhidas duas plantas, por parcela, as quais foram cortadas rentes ao solo, e conduzidas ao laboratório, para determinação da altura de plantas (AP), diâmetro da haste (DH) e massa seca da parte aérea (MSPA). Para determinar AP, usou uma régua comum, medindo do colo até meristema apical da planta, e com auxílio de um paquímetro digital obteve-se a DH. A MSPA foi obtida, após o acondicionamento das plantas em sacos de papéis, seguido da secagem em estufa de renovação e circulação forçada de ar a $65{ }^{\circ} \mathrm{C}$ por 72 horas, até atingir massa constante, e posteriormente, pesadas.

Aos 46 DAE foram realizadas a determinação dos teores de clorofila, entre as 14:00h e 15:30h, através de 5 leituras por parcela, da folha do terço médio da planta, realizadas com ClorofiLOG 1030.

Aos $85 \mathrm{DAE}$, foram coletadas e contabilizadas as plantas situadas em quatro metros lineares das duas linhas centrais, as quais foram expostas ao sol, e aos $90 \mathrm{DAE}$, procedeu-se o processo de trilhagem manual, para determinação da produtividade da cultura. Dez (10) plantas foram colhidas na área útil da parcela para estimar o número de vagens por planta (NVP) e de grãos por planta (NGP) e a massa de mil grãos (MMG).

Aos $85 \mathrm{DAE}$, dois quadrados vazados, com dimensão de $(0,5 \times 0,5 \mathrm{~m})$ foram lançados ao acaso para determinação da palhada remanescente. A palha situada no interior foi cortada com auxílio de tesoura de corte acondicionadas em sacos de papel e conduzidos a estufa de renovação e circulação forçada de ar a $65{ }^{\circ} \mathrm{C}$ por 72 horas ou até atingir massa constante, e posteriormente pesadas em balança de precisão.

Os resultados foram submetidos à análise de variância, e quando significativos, as 
médias foram contrastadas pelo teste de Tukey, a $5 \%$ de probabilidade, por meio do software Sisvar versão 5.6.

\section{Resultados e Discussão}

A comunidade de plantas daninhas na cultura do feijão-caupi foi composta pelas espécies Emilia fosbergii (falsa-serralha), Synedrellopsis grisebachii (agriãozinho), Acanthospermum hispidum (carrapicho-decarneiro), Ageratum conyzoides (mentrasto), Galinsoga parviflora (botão-de-ouro) pertencente à família das Asteraceae, seguida da família das Poaceae, representado pelas espécies: Panicum maximum (capim-colonião), Cenchrus echinatus (capim-carrapicho), Digitaria insularis (capimamargoso), Eleusine indica (capim-pé-de-galinha) e Digitaria horizontalis (capim-colchão); Amaranthaceae: Alternanthera tenella (apagafogo); seguido da família das Fabaceae, composto pelas espécies: Desmodium tortuosum (desmódio); Commelinaceae: Commelina benghalensis (trapoeraba); seguido da família das Papaveraceae: Argemone mexicana (papoula-doméxico); seguido da família das Solanaceae: Nicandra physaloides (joá-de-capote); seguido da família das Portulacaceae: Portulaca oleraceae (beldroega); e por último a família das Cyperaceae: Cyperus rotundus (tiririca-do-brejo). As espécies dominantes foram: Nicandra physaloides, Alternanthera tenella, Eleusine indica, Commelina benghalensis e Digitaria insularis, respectivamente.

Foram constatadas interações significativas entre as palhadas das plantas de cobertura e a aplicação de herbicidas para a densidade e massa seca das plantas daninhas avaliadas aos 20 e aos 85 DAE (Tabela 1). Nas parcelas não tratadas com herbicidas, a densidade inicial de plantas daninhas foi diminuída sobre as palhadas de capim-tanzânia e de capim-ruziziensis em relação às demais palhadas (Tabela 1). Torna-se evidente, que o tipo de palhada influenciou a infestação inicial em função dos efeitos relacionados à espessura da palhada e sua distribuição sobre o solo, bem como aos efeitos alelopáticos (NOCE et al., 2010).

Para a massa seca de plantas daninhas aos 20 e 85 DAE, observa-se que na ausência da aplicação de herbicidas, os efeitos das palhadas dos capins foram superiores ao tratamento em pousio, mostrando que a palhada vegetal auxilia na redução da infestação, com exceção a palhada de sorgo que apresentou valor estatisticamente igual ao da testemunha aos 85 DAE (Tabela 1).

Lima et al. (2014) reportaram que a palhada de $U$. ruziziensis nas quantidades de 6,5 e $8,5 \mathrm{t} \mathrm{ha}^{-1}$ suprimiu a infestação de plantas daninhas na cultura da soja, quando comparada à vegetação espontânea, embora ainda fora necessária a complementação no controle com o uso de herbicidas. No cultivo do feijão-comum, Nunes et al. (2006) constataram que a permanência de palhadas de gramíneas em sistemas de cultivo, é resultado da alta relação $\mathrm{C} / \mathrm{N}$ e do alto teor de lignina da sua palha, o que pode resultar em lenta mineralização, produzindo efeitos benéficos a longo prazo, como a supressão de plantas daninhas. 
Tabela 1. Valores médios de densidade (DP) e massa seca (MS) de plantas daninhas na cultura do feijãocaupi avaliadas aos 20 e 85 dias após a emergência (DAE) da cultura em função dos tipos de palhadas e da aplicação de herbicidas

\begin{tabular}{|c|c|c|c|c|c|c|}
\hline \multicolumn{7}{|c|}{ Avaliação aos 20 dias após a emergência (DAE) } \\
\hline \multirow{3}{*}{ Palhadas } & \multicolumn{3}{|c|}{$\mathrm{DP}\left(\right.$ plantas $\left.\mathrm{m}^{-2}\right)$} & \multicolumn{3}{|c|}{$\mathrm{MS}\left(\mathrm{g} \mathrm{m}^{-2}\right)$} \\
\hline & \multicolumn{2}{|c|}{ Herbicidas } & \multirow{2}{*}{ Médias } & \multicolumn{2}{|c|}{ Herbicidas } & \multirow{2}{*}{ Médias } \\
\hline & Sem & Com & & Sem & Com & \\
\hline Sorgo & $38,0 \mathrm{bB} *$ & $4,0 \mathrm{aA}$ & 21,0 & $24,80 \mathrm{abA}$ & $1,01 \mathrm{aA}$ & 12,90 \\
\hline Capim-ruziziensis & $25,0 \mathrm{abB}$ & 7,3 aA & 16,7 & 39,17 bB & $0,21 \mathrm{aA}$ & 19,69 \\
\hline Capim-tanzânia & 10,7 aA & $6,7 \mathrm{aA}$ & 8,7 & $3,91 \mathrm{aA}$ & $0,25 \mathrm{aA}$ & 2,08 \\
\hline Capim-marandu & $34,7 \mathrm{bB}$ & $7,7 \mathrm{aA}$ & 21,2 & $22,19 \mathrm{abA}$ & $1,82 \mathrm{aA}$ & 12,01 \\
\hline Pousio & $37,3 \mathrm{bB}$ & $4,7 \mathrm{aA}$ & 21,0 & $95,58 \mathrm{cB}$ & 5,49 aA & 50,54 \\
\hline Médias & 29,1 & 6,1 & & 37,13 & 1,76 & \\
\hline CV (\%) & & & & & 7,02 & \\
\hline \multicolumn{7}{|c|}{ após a emergência DAE } \\
\hline Sorgo & $35,0 \mathrm{aB}$ & 8,0 aA & 21,5 & $146,90 \mathrm{bB}$ & $0,50 \mathrm{aA}$ & 79,02 \\
\hline Capim-ruziziensis & $16,7 \mathrm{aA}$ & $13,0 \mathrm{aA}$ & 14,8 & 77,96 aB & $2,02 \mathrm{aA}$ & 39,99 \\
\hline Capim-tanzânia & 21,7 aA & $4,7 \mathrm{aA}$ & 13,1 & 37,15 aA & $0,01 \mathrm{aA}$ & 18,58 \\
\hline Capim-marandu & 32,7 aA & 12,0 aA & 22,3 & $57,37 \mathrm{aB}$ & $2,77 \mathrm{aA}$ & 30,07 \\
\hline Pousio & $68 \mathrm{bB}$ & 11,0 aA & 39,5 & $178,71 \mathrm{bB}$ & 4,79 aA & 91,75 \\
\hline Médias & 34,8 & 9,7 & - & 99,62 & 2,02 & - \\
\hline CV (\%) & \multicolumn{2}{|c|}{32,06} & & \multicolumn{2}{|c|}{22,39} & \\
\hline
\end{tabular}

* Médias seguidas pelas mesmas letras minúsculas entre as linhas e maiúsculas entre colunas são estatisticamente iguais pelo teste de Tukey $(p<0,05)$.

A associação de herbicidas ([bentazona + imazamoxi] + haloxifope-p-metílico) demonstrouse segura ao cultivar BRS Guariba e eficaz no controle de plantas daninhas. Estes resultados concordam com os observados por Silva et al. (2014) que verificaram aos 28 dias após a semeadura, o controle excelente (100\%) para as plantas daninhas Cleome affinis, Amaranthus spinosus, Digitaria bicornis e Commelina benghalensis e seletividade para a cultivar BRS Guariba, quando tratado com [bentazona + imazamoxi] + fluazifop-p-butil.

Aos $85 \mathrm{DAE}$, a redução na densidade de plantas daninhas pelas palhadas de capimzuziziensis, capim-tanzânia e capim-marandu assemelharam-se ao controle efetuado pelos herbicidas (Tabela 1). Estes resultados concordam com Braz et al. (2006) que relatam que o capimmarandu ou braquiarão e mombaça $(P$. maximum) se mostraram mais promissoras em relação a outras palhadas em reduzir a emergência de plantas daninhas em cultivos subsequentes, apresentando resultados significativos na diminuição do número de plantas daninhas de Euphorbia heterophylla estabelecidas nas áreas cultivadas com feijão carioca.

O menor acúmulo de massa seca de plantas daninhas foi observado com a aplicação de herbicidas nas avaliações feitas aos 20 e 85 DAE (Tabela 1). Aos 20 e aos 85 DAE na ausência do controle químico, de forma geral, as palhadas dos capins contribuíram para o menor acúmulo de massa seca das plantas daninhas em relação ao pousio, evidenciando a interferência destas na germinação e crescimento de plantas daninhas, constituindo uma opção para o manejo integrado de plantas daninhas, principalmente em áreas que apresentam alta incidência de plantas daninhas de difícil controle. Todavia, verifica-se que aos 85 DAE houve a necessidade da complementação de controle com o uso de herbicidas para as diferentes coberturas de solo, a exceção observada para o capim-tanzânia (Tabela 1).

A maior densidade e massa seca de plantas daninhas foram observadas em solo com cobertura de plantas daninhas (pousio), o que gerou maior interferência de plantas daninhas na cultura se comparado ao sistema de cultivo em solos cobertos por palhadas de gramíneas. De acordo com Castro et al. (2011), trabalhando com 
diferentes sistemas de produção, observaram que a inserção de forrageiras no sistema produtivo tanto da soja quanto do milho pode proporcionar controles da comunidade infestante, superiores a $97 \%$.

As quantidades de palhada proveniente das culturas de cobertura mensurada por ocasião da colheita do feijão-caupi são apresentadas na Tabela 2. Foi observado apenas efeitos isolados para tipos de coberturas, no qual a palhada proveniente do capim-tanzânia foi a mais produtiva entre os capins, os quais foram estatisticamente iguais e superiores a palhada proveniente do pousio, o que explica os resultados de redução de massa seca de plantas daninhas aos 85 DAE, observados na Tabela 1.

De acordo com Tokura e Nóbrega (2005), a principal forma de supressão de uma planta de cobertura, é a supressão física, o que é resultado do volume de palha produzido pela mesma, e pela capacidade de permanência no solo.
Resultados contrastantes foram encontrados por Garcia et al. (2014), onde trabalhando com a decomposição de palhada de Urochloa brizantha cv. Xaraés, Urochloa ruziziensis, Panicum maximum cv. Tanzânia e Mombaça, estabelecida simultaneamente ao milho, em função da adubação nitrogenada, não verificaram diferença significativa para a massa seca de palhada das plantas de cobertura, o que pode ser resultado do consórcio entre as plantas de cobertura e o milho ter desfavorecido a produção de massa seca de algumas forrageiras menos tolerantes ao sombreamento, como é o caso das cultivares do gênero Panicum. Já Timossi et al. (2007), trabalhando com a formação de palhadas de Brachiaria decumbens e B. brizantha e Pennisetum glaucum, constataram que as forrageiras apresentam maior produção de massa seca do que o milheto, demonstrando diferença no volume entre as espécies gramíneas.

Tabela 2. Valores médios de massa seca das palhadas (MSP) avaliadas por ocasião da colheita da cultura em função dos tipos de palhadas e da aplicação de herbicidas

\begin{tabular}{cccc}
\hline \multirow{2}{*}{ Palhadas } & \multicolumn{3}{c}{ MSP $\left(\mathrm{g} \mathrm{m}^{-2}\right)$} \\
\cline { 2 - 3 } & \multicolumn{2}{c}{ Herbicidas } & \multirow{2}{*}{ Médias } \\
\cline { 2 - 3 } & Sem & Com & $103,80 \mathrm{~b}$ \\
Sorgo & 103,53 & 104,07 & $126,47 \mathrm{~b}$ \\
Capim-ruziziensis & 141,53 & 111,40 & $212,67 \mathrm{a}$ \\
Capim-tanzânia & 206,20 & 219,13 & $110,17 \mathrm{~b}$ \\
Capim-marandu & 102,33 & 118,00 & $26,70 \mathrm{c}$ \\
\hline Pousio & 25,80 & 27,60 & \\
\hline Médias & $115,88 \mathrm{~A}$ & $116,04 \mathrm{~A}$ \\
\hline CV (\%) & \multicolumn{3}{c}{36,72} \\
\hline
\end{tabular}

* Médias seguidas pelas mesmas letras minúsculas entre as linhas e maiúsculas entre colunas são estatisticamente iguais pelo teste de Tukey $(p<0,05)$.

Em relação as plantas de feijão-caupi não foram observadas efeitos dos tratamentos sobre os teores de clorofila $a$ e $b$, e para o DH (Tabela 3). Para a AP foi observada interação significativa, com efeitos negativos proporcionados pela palhada proveniente do pousio em relação a palhada de sorgo, quando não se aplica herbicida. Da mesma forma, para os feijoeiros cultivados sobre palhada proveniente do pousio foi necessário a aplicação de herbicidas para se obter plantas de feijão mais altas. Este efeito pode estar associado a interferência promovida pelas plantas daninhas neste sistema de cultivo, que afetou esta variável na ausência do controle químico.

Pereira et al. (2019), trabalhando com períodos de interferência de $U$. brizantha no município de Rio Verde, ressaltam que a competição entre plantas daninhas e a cultura pode resultar em alteração de componentes de crescimento dependendo da espécie infestante e da espécie cultivada.

Gomes et al. (2014), trabalhando com o efeito de palhadas de sorgo e crotalária na supressão de plantas daninhas, verificaram que a palhada de sorgo suprime algumas espécies infestantes específicas, como: Euphorbia heterophylla, Ipomoea acuminata e Cenchrus echinatus, o que favoreceu a altura de plantas de feijão-caupi no presente experimento, em relação ao tratamento em pousio.

A não diferença estatística para as 
clorofilas $a$ e $b$, pode relacionar com a taxa de decomposição similar entre as palhadas testadas, resultando em disponibilidade de nutrientes similares para síntese de clorofila pelas plantas de feijão-caupi (DAMASCENO, 2019).

Tabela 3. Valores médios de altura de plantas (AP), diâmetro da haste (DH) e teores de clorofila $a$ e $b$ (Clorofilog) de plantas de feijão-caupi em função dos tipos de palhada e aplicação de herbicidas

\begin{tabular}{|c|c|c|c|c|c|c|}
\hline \multirow{3}{*}{ Palhadas } & \multicolumn{3}{|c|}{$\mathrm{AP}(\mathrm{cm})$} & \multicolumn{3}{|c|}{$\mathrm{DH}(\mathrm{mm})$} \\
\hline & \multicolumn{2}{|c|}{ Herbicidas } & \multirow{2}{*}{ Médias } & \multicolumn{2}{|c|}{ Herbicidas } & \multirow{2}{*}{ Médias } \\
\hline & Sem & Com & & Sem & Com & \\
\hline Sorgo & $61,67 \mathrm{aA}$ & 62,67 aA & 62,17 & 7,57 & 8,33 & $7,95 a$ \\
\hline Capim-ruziziensis & $54,50 \mathrm{abA}$ & 57,33 aA & 55,91 & 6,97 & 7,97 & $7,47 \mathrm{a}$ \\
\hline Capim-tanzânia & $54,83 \mathrm{abA}$ & 57,67 aA & 56,25 & 7,40 & 8,20 & $7,80 \mathrm{a}$ \\
\hline Capim-marandu & $53,17 \mathrm{abA}$ & 56,67 aA & 53,42 & 6,83 & 8,00 & $7,42 \mathrm{a}$ \\
\hline Pousio & 44,17 bB & 60,27 aA & 52,22 & 8,93 & 7,47 & $8,20 \mathrm{a}$ \\
\hline Médias & 53,70 & 58,32 & & $7,54 \mathrm{~A}$ & $7,99 \mathrm{~A}$ & \\
\hline \multirow[t]{2}{*}{ CV (\%) } & \multicolumn{2}{|c|}{8,23} & & \multicolumn{3}{|c|}{27,02} \\
\hline & \multicolumn{3}{|c|}{ Clorofila $a$} & \multicolumn{3}{|c|}{ Clorofila $b$} \\
\hline Sorgo & 40,11 & 41,32 & $40,72 a$ & 20,08 & 21,48 & $20,78 a$ \\
\hline Capim-ruziziensis & 40,75 & 40,50 & $40,63 \mathrm{a}$ & 20,56 & 21,12 & $20,84 \mathrm{a}$ \\
\hline Capim-tanzânia & 40,00 & 39,98 & $39,99 a$ & 20,50 & 20,39 & $20,44 a$ \\
\hline Capim-marandu & 41,24 & 41,05 & $41,14 a$ & 21,47 & 21,98 & $21,72 \mathrm{a}$ \\
\hline Pousio & 40,21 & 39,87 & $40,04 \mathrm{a}$ & 21.28 & 22,65 & $21,97 \mathrm{a}$ \\
\hline Médias & $40,46 \mathrm{~A}$ & $40,54 \mathrm{~A}$ & & $20,77 \mathrm{~A}$ & $21,52 \mathrm{~A}$ & \\
\hline CV (\%) & \multicolumn{2}{|c|}{3,04} & & \multicolumn{2}{|c|}{11,95} & \\
\hline
\end{tabular}

* Médias seguidas pelas mesmas letras minúsculas entre as linhas e maiúsculas entre colunas são estatisticamente iguais pelo teste de Tukey $(p<0,05)$.

Para a MSPA avaliada aos 46 dias após a emergência (DAE) foi verificado que independente da palhada, o controle de plantas daninhas promovida pelos herbicidas aplicados em pós-emergência contribui para maior valor da MSPA em relação as parcelas não tratadas (Tabela 4), que também refletiu no número de grãos por vagem (NGP) e no rendimento de grãos (RG). Entre as palhadas foram observados, independente da aplicação dos herbicidas em pós-emergência, efeitos significativos para NGP e RG, demonstrando superioridade a favor da cultura cultivada sobre palhadas de capimmarandu, sorgo e capim-tanzânia, em detrimento a palhada proveniente do pousio. Estes resultados concordam com Nunes et al. (2006) que constataram que a utilização de gramíneas como espécies de plantas de cobertura, com intuito de viabilizar a formação de palhada para o sistema de plantio direto, permite a obtenção de maiores rendimentos da cultura do feijão.

Para a população de plantas (PO), número de grãos por vagem (NGP) e massa de mil grãos (MMG) não foram observados efeitos de tratamentos (Tabela 4). Pereira et al. (2020), trabalhando com a seletividade de herbicidas para a cultura do feijão-caupi, constataram que as variáveis MMG, e NGP são poucas influenciadas pela matocompetição e/ou herbicidas testados, enquanto que a população de plantas pode sofrer alterações de acordo com a intensidade de competição promovida pela comunidade infestante. 
Tabela 4. Valores médios de massa seca da parte aérea (MSPA), população de plantas (PO), número de grãos por vagens (NGV), número de grãos por planta (NGP), massa de mil grãos (MMG) e rendimento de grãos (RG) de plantas de feijão-caupi cultivado sobre diferentes palhadas e aplicação de herbicidas

\begin{tabular}{|c|c|c|c|c|c|c|}
\hline \multirow{3}{*}{ Palhadas } & \multicolumn{3}{|c|}{ MSPA $\left(\mathrm{g} \mathrm{m}^{-2}\right)$} & \multicolumn{3}{|c|}{ PO (plantas ha ${ }^{-1}$ ) } \\
\hline & \multicolumn{2}{|c|}{ Herbicidas } & \multirow{2}{*}{ Médias } & \multicolumn{2}{|c|}{ Herbicidas } & \multirow{2}{*}{ Médias } \\
\hline & Sem & Com & & Sem & Com & \\
\hline Sorgo & 20,54 & 25,26 & 22,90 & 342.592 & 340.740 & 341.666 \\
\hline Capim-ruziziensis & 18,12 & 20,97 & 19,55 & 302.777 & 318.518 & 310.648 \\
\hline Capim-tanzânia & 19,33 & 22,68 & 21,00 & 304.629 & 317.592 & 311.110 \\
\hline Capim-marandu & 20,16 & 21,76 & 20,97 & 298.148 & 298.148 & 298.148 \\
\hline Pousio & 8,57 & 21,12 & 14,84 & 274.999 & 296.296 & 285.648 \\
\hline Médias & $17,34 \mathrm{~B}$ & $22,36 \mathrm{~A}$ & - & 304.629 & 314.259 & \\
\hline \multirow[t]{2}{*}{ CV (\%) } & \multicolumn{2}{|c|}{22,73} & & & 11,31 & \\
\hline & \multicolumn{3}{|c|}{ NGV } & \multicolumn{3}{|c|}{ NGP } \\
\hline Sorgo & 5,7 & 6,9 & $6,3 a$ & 34,3 & 44,4 & $39,4 a$ \\
\hline Capim-ruziziensis & 5,4 & 4,5 & $4,9 a b$ & 36,4 & 29,7 & $33,0 a b$ \\
\hline Capim-tanzânia & 6,2 & 7,1 & $6,4 \mathrm{a}$ & 38,4 & 48,3 & $43,5 \mathrm{a}$ \\
\hline Capim-marandu & 6,2 & 6,5 & $6,4 \mathrm{a}$ & 38,6 & 42,2 & $40,3 \mathrm{a}$ \\
\hline Pousio & 1,8 & 5,0 & $3,4 \mathrm{~b}$ & 8,5 & 28,5 & $18,5 \mathrm{~b}$ \\
\hline Médias & 5,0 & 6,0 & & $31,2 \mathrm{~B}$ & $38,6 \mathrm{~A}$ & \\
\hline \multirow[t]{2}{*}{ CV (\%) } & \multicolumn{2}{|c|}{22,52} & & \multicolumn{2}{|c|}{25,31} & 34,3 \\
\hline & \multicolumn{3}{|c|}{ MMG (g) } & \multicolumn{3}{|c|}{ RG $\left(\mathrm{kg} \mathrm{ha}^{-1}\right)$} \\
\hline Sorgo & 189,80 & 199,40 & 194,56 & 1280,39 & 1287,02 & $1283,70 \mathrm{a}$ \\
\hline Capim-ruziziensis & 201,44 & 199,66 & 200,55 & 954,58 & 1118,62 & $1071,60 a b$ \\
\hline Capim-tanzânia & 190,59 & 200,15 & 195,37 & 1240,36 & 1367,23 & $1303,88 a$ \\
\hline Capim-marandu & 201,44 & 199,86 & 200,66 & 955,04 & 1433,97 & $1194,50 \mathrm{a}$ \\
\hline Pousio & 194,53 & 220,30 & 207,41 & 813,42 & 965,18 & $889,30 \mathrm{~b}$ \\
\hline Médias & 195,56 & 203,87 & & $1048,76 \mathrm{~B}$ & $1248,40 \mathrm{~A}$ & \\
\hline CV (\%) & \multicolumn{3}{|c|}{5,80} & \multicolumn{3}{|c|}{12,49} \\
\hline
\end{tabular}

* Médias seguidas pelas mesmas letras minúsculas entre as linhas e maiúsculas entre colunas são estatisticamente iguais pelo teste de Tukey $(p<0,05)$.

\section{Conclusões}

As palhadas dos capim-ruziziensis, capimtanzânia e capim-marandu contribuem no manejo integrado de plantas daninhas pela reduzindo a população da comunidade infestante na cultura do feijão-caupi.

Dependendo do tipo de palhada, como de sorgo ou proveniente do pousio, há necessidade de complementação do controle de plantas daninhas por meio de herbicidas.

Independente do uso de herbicidas, o cultivo de feijão-caupi sobre as palhadas de capins favorece o rendimento da cultura em relação ao cultivo sobre palhada remanescente de pousio.

\section{Referencias}

BRASIL. Companhia Nacional de Abastecimento. Boletim da safra de grãos: safra 2017/18 - n. 11 - décimo levantamentos, agosto 2018, 2019. Disponível em: https://www.conab.gov.br/infoagro/safras/graos/boletim-da-safra-de-graos; Acesso em: 23 jun. 2019.

BRAZ, A. J. B. P.; PROCÓPIO, S. O.; CARGNELUTTI FILHO, A.; SILVEIRA, P. M.; KLIEMANN, H. J.; COBUCCl, T.; BRAZ, G. B. P. Emergência de plantas daninhas em lavouras de feijão e de trigo após o cultivo de espécies de cobertura de solo. Planta Daninha, v. 24, n. 4, p. 621-628, 2006. https://doi.org/10.1590/S0100$\underline{83582006000400002}$

CASTRO, G. S. A.; CRUSCIOL, C. A. C.; NEGRISOLI, E.; PERIM, L. Sistemas de produção de grãos e incidência de plantas daninhas. Planta Daninha, 
p. 1001-1010, 2011.

https://doi.org/10.1590/S0100-

$\underline{83582011000500006}$

CORRÊA, M. J. P.; ALVES, G. L.; ROCHA, L. G. F.; SILVA, M. R. M. Períodos de interferência de plantas daninhas na cultura do feijão caupi. Revista de Ciências Agroambientais, v. 13, n. 2, p. 50-56, 2016.

CORREIA, N. M.; DURIGAN, J. C.; KLINK, U. P. Influência do tipo e da quantidade de resíduos vegetais na emergência de plantas daninhas. Planta Daninha, v. 24, n. 2, p. 245-253, $2006 . \quad$ https://doi.org/10.1590/S010083582006000200006

DAMASCENO, L. A. Produtividade do milho em sucessão a plantas de cobertura de solo. 2019. 69 f. Tese (Doutorado em Agronomia Tropical) Universidade Federal do Amazonas, Manaus, 2019.

FREIRE FILHO, F. R.; RIBEIRO, V. Q.; ROCHA, M. M.; SILVA, K. J. D.; NOGUEIRA, M. S. R.; RODRIGUES, E. V. Feijão-caupi no Brasil: produção, melhoramento genético, avanços e desafios. Teresina: Embrapa Meio-Norte, 2011. $84 \mathrm{p}$.

FREITAS, F. C. L.; MEDEIROS, V. F. L. P.; GRANGEIRO, L. C.; SILVA, M. G. O.; NASCIMENTO, P. G. M. L.; NUNES, G. H. Interferência de plantas daninhas na cultura do feijão-caupi. Planta Daninha, v. 27, n. 2, p. 241-247, 2009.

https://doi.org/10.1590/s010083582009000200005

GARCIA, C. M. P.; ANDREOTTI, M.; TEIXEIRA FILHO, M. C. M.; LOPES, K. S. M.; BUZETTI, S. Decomposição da palhada de forrageiras em função da adubação nitrogenada após o consórcio com milho e produtividade da soja em sucessão. Bragantia, v. 73, n. 2s, p. 143-152, 2014. https://doi.org/10.1590/brag.2014.016

GOMES, D. S.; BEVILAQUA, N. C.; SILVA, F. B.; MONQUERO, P. A. Supressão de plantas espontâneas pelo uso de cobertura vegetal de crotalária e sorgo. Revista Brasileira de Agroecologia, v. 9, n. 2, p. 206-2013, 2014.

LIMA, S. F.; TIMOSSI, P. C.; ALMEIDA, D. P.; SILVA, $U$. R. Weed suppression in the formation of brachiarias under three sowing methods. Planta Daninha, v. 32, n. 4, p. 699-707, 2014.

https://doi.org/10.1590/S0100-

$\underline{83582014000400004}$

MATOS, V. P.; SILVA, R. F.; VIEIRA, C.; SILVA, J. F. Período crítico de competição entre plantas daninhas e a cultura do caupi. Pesquisa Agropecuária Brasileira, Brasília, v. 26, n. 5, p. 737-743, 1991.

NOCE, M. A.; SOUZA, I. F. de; KARAM, D.; FRANÇA, A. G.; MACIEL, G. M. Influência da palhada de gramíneas forrageiras sobre o desenvolvimento da planta de milho e das plantas daninhas. Revista Brasileira de Milho e Sorgo, v. 7, n. 03, 2010.

https://doi.org/10.18512/1980-

6477/rbms.v7n3p265-278

NUNES, U. R.; ANDRADE JÚNIOR, V. C.; SILVA, E. B.; SANTOS, N. F.; COSTA, H. A. O.; FERREIRA, C. A. Produção de palhada de plantas de cobertura e rendimento do feijão em plantio direto. Pesquisa Agropecuária Brasileira, v. 41, n. 6, p. 943-948, $2006 . \quad$ https://doi.org/10.1590/S0100$\underline{204 \times 2006000600007}$

PEREIRA, L. S.; JAKELAITIS, A.; OLIVEIRA, G. S.; SOUSA, G. D.; SILVA, J. N.; COSTA, E. M. Interferência de plantas daninhas em pastagem de Urochloa brizantha cv. Marandu. Revista Cultura Agronômica, v. 28, n. 1, p. 29-41, 2019. https://doi.org/10.32929/24468355.2019v28n1p29-41

PEREIRA, L. S.; SOUSA, G. D.; OLIVEIRA, G. S.; SILVA, J. N.; COSTA, E. M.; VENTURA, M. V. A.; JAKELAITIS, A. Eficiência de herbicidas aplicados em pós-emergência na cultura do feijão-caupi. Colloquium Agrariae, v. 16, n. 1, p. 29-42, 2020. https://doi.org/10.5747/ca.2020.v16.n1.a345

RIBEIRO, V. Q.; JÚNIOR, A. S. D.; SANTOS, A. A.; SOBRINHO, C. A.; BASTOS, E. A.; MELO, F. B.; VIANA, F. M. P.; FILHO, F. R. F.; CARNEIRO, J. S.; ROCHA, M. M., CARDOSO, M. J.; SILVA, P. H. S. Cultivo do feijão-caupi (Vigna unguiculata (L.) Walp). Teresina: Embrapa Meio-Norte, 2002. P.11-17.

SILVA, K. S.; FREITAS, F. C. L.; SILVEIRA, L. M.; LINHARES, C. S.; CARVALHO, D. R.; LIMA, M. F. P. Eficiência de herbicidas para a cultura do feijão- 
caupi. Planta Daninha, v. 32 , n. 1, p. 197-205,

2014.

https://doi.org/10.1590/S0100-

$\underline{83582014000100022}$

TIMOSSI, P. C.; DURIGAN, J. C.; LEITE, G. J. Formação de palhada por braquiárias para adoção do sistema plantio direto. Bragantia, v. 66, n. 4, p. 617-622, 2007.

https://doi.org/10.1590/S0006-

$\underline{87052007000400012}$

TOKURA, L. K.; NÓBREGA, L. P. Potencial alelopático de cultivos de cobertura vegetal no desenvolvimento de plântulas de milho. Acta Scientiarum - Agronomy, Maringá, v. 27, n. 2, p. 287-292, abril/junho, 2005.

https://doi.org/10.4025/actasciagron.v27i2.1847 